\title{
Analysis of the use of digital technologies in the activities of educational organizations in the conditions of distance learning (from the experience of France)
}

\author{
Vasilina Anatolevna Kastornova ${ }^{1}$, and Natalia Viktorovna Gerova ${ }^{2, *}$ \\ ${ }^{1}$ Federal State Budgetary Scientific Institution "Institute of Education Development Strategy of the \\ Russian Academy of Education" \\ ${ }^{2}$ Federal State Budgetary Educational Institution of Higher Education "Ryazan State University \\ named after S.A. Esenin", Svoboda street, 46, 390000 Ryazan, Russia
}

\begin{abstract}
The article deals with the issues of setting up and developing distance learning technology in France on the example of the National Center for Distance Education (CNED). The organizational forms of its implementation are given, the role of digital educational resources and digital work space in realization of distance learning is shown.
\end{abstract}

\section{Introduction}

The General Inspectorate of National Education of France in the 1999-2000 academic year formulated the concept: "Distance learning: its contribution to the success of students" (L'enseignement a distance; sa contribution a la reussite des eleves» [5]. For a very long time in France, distance learning was considered only as palliative (different, opposite), different from traditional "face-to-face" education. This type of education was applied only in that case when physical presence of the student in the educational institution was challenging due to various reasons: sickness, inability to move, disability etc. Thus, statutory education led to the creation of the national school system "outside the walls" so that everyone could visit educational institutions in those cases that considered exceptional, when internal mode of study in an educational institution is impossible. First, the concept of distance learning led to creation of an external mode of study, later it just came down to "absence in class". Thus, at school (middle and senior) there was traditional education with pedagogics (though there are exceptions in case of home schooling) and distance learning, which at that time was of an exceptional nature.

This concept of distancing (remoteness) was given a boost due to the development of information and communication technologies and the emergence of computer networks. It is known that remoting can be synchronous (on-line) or asynchronous (off-line). So, an example of synchronous remoting (real-time mode) can be a video-conference, while the asynchronous remoting (delayed mode) can be manifested as a teleconference or e-mail. This trend led to creation of the National Center of distance learning (le Centre national

\footnotetext{
*Corresponding author: nat.gerova@gmail.com
} 
d'enseignement a distance - CNED) in the system of education of France, which has taken over the functions of studying these new forms of national education that are developing, and which have been made possible by the spread of digital communication and methods of remote communication. The status and the functionality of the state body engaged in the development and implementation of distance learning are defined in [3].

The National Center of distance learning is a national state administrative institution, which is under control of the Ministry of national education, higher education and science. Whether it is initial training (primary school, college, high school), resuming studies or continuing professional training, CNED can offer an appropriate solution to all those who have a training project, regardless of age and social status.

CNED offers to students individual support on the part of professors and supervisors from the national system of education (by phone or e-mail). After registration, you get an access to the educational web-site that can include forums for the exchange of messages between registered users, exercises, self-evaluation, test homeworks on education, additional resources, pieces of advice on organization of education and more effective management of education. Depending on your needs, as an option, you can staff groups present at one of the CNED partner centers near you or choose additional phone support (internship monitoring, oral test preparation) [3].

CNED celebrated its seventieth anniversary in 2019. Nowadays, the state institution under control of the Ministry of national education that was created in 1939 for all those who for various reasons could not get education in an educational institution (sickness, distance, high-level sports activities etc.) became one of the most important organizations of distance learning in the world and, undoubtedly, first among French-speaking countries. This organization not only performs the function of public service and social support but also retrains teachers who suffer from illness or disability, which helps them to keep their working life. Finally, CNED has methodological and educational materials for all employees of the education system (teachers, university teachers, teachers-librarians, management and administrative staff) on the informatization of all levels of their professional activities. CNED's activities also extend to universities and upper secondary schools.

\section{Organization of distance learning on the base of digital technologies in France}

Distance learning has significantly changed during recent years, it became a modern pedagogical practice capable to upgrade both initial education and education for adults who are already engaged in labor. Over the past decade, this phenomenon has been reinforced by a combination of two factors: the exceptional growth in demand for training for young people and adults, and the accelerated development of communication methods based on digital technologies and the Internet. On the first point, for both industrialized and developing countries, the modernization and dissemination of education have become the main strategic objectives. Global (worldwide) market of education has become real. France is an integral part of this market, and now CNED perform an important mission - demonstration of the French education abroad for knowledge export. On the second point, methods of digital communication offer significantly expanded opportunities for access to electronic educational resources and interactive information interaction.

It means that modern distance learning gradually loses its nature as of additional education so to more and more assert itself as a natural way of learning, which is combined with traditional internal mode of study. Thanks to the technologies and methodics developed by CNED, it helps to offer an alternative or an addition to the traditional (internal) system of education. 
The social evolution faced by the education system (mass character, growing heterogeneity), the complexity of individualization of the learning process lead to a constant search for new pedagogical techniques. In most cases working on classical pedagogical schemes of education, school did not yet fully realize the possibilities offered by information and communication technologies, although we can see many examples of new and diverse educational applications of information and communication technologies (ICTs). Nevertheless, new pedagogical models of behaviour appear in which remote action has a direct impact, when face-to-face communication is replaced with a distant one, it leads to the idea of developing so-called "virtual classrooms". It leads to changes in human behaviour and relationships between participants of the education process. They concern both relationships between teachers and relationships between teachers and students and relationships between students located in different classrooms, both in their own country and in foreign countries. It is clear illustration of the broader opportunities offered by ICTs and the Internet.

It should be noted that distant services in France are not solely provided by the CNED structure. More and more schools and other educational institutions, following the methodics elaborated in CNED, provide in the Internet their moral and pedagogical help to the disabled, the hospitalized and professional athletes to study at distance by communicating with teachers of an educational institution, curriculum of which takes these specific conditions into account.

Distance learning not only facilitates access to educational services but also affects the process of education itself. Naturally, distance learning significantly changes approach to evaluation of knowledge of students. Here, there are no traditional marks or points that are obtained by students in internal mode of study, a special attention is paid to cultural (such as citizenship, cooperation etc.) and disciplinary aspects. It leads to the different principle of forming an assessment to monitor the progress and success of students. According to experts, assessment of knowledge of students should be concentrated on passing final exams [5].

Higher education is not included in the scope of CNED activities, this center is focused more on secondary education. But it works closely with the University institute for Teacher Training (Institut Universitaire de Formation des Maitres - IUFM), whose task is to train future teachers, including the forms of organization of distance learning, which should become one of the components of their future professional activity. Training of teachers requires more and more special training to these new types of work.

Today, digital communication radically transforms distance learning. It is no longer a default education, a legal remedy or a facilitation of the learning process itself. It has become one more, additional way of education. CNED provides training not only to its regular audience of students who cannot or are not allowed to attend a regular school, but also to students studying in educational institutions in search of additional training.

As a guarantor of civil service policy, an important factor in France's presence abroad, CNED has become a significant player in national education and a platform in which new educational products are created. This, in a sense, is at the heart of the modernization of the French education system. A public institution subordinate to the Ministry of education, CNED, through its activities, is engaged in the public education service. Currently, its activities are focued not only on students with special learning needs, as it was before, but also covers the regular school. CNED carries out these activities under the general control of the Department of educational policy (Direction de la politique pedagogique-DPP).

DPP defines main directions of educational policy for a two-year period and reduces them to the goals of preparing training conferences, which are held at the end of the school year. During these conferences, various institutes as well as general management offer activities that may be elaborated and registered in the road map. Department of educational 
policy verifies road maps, controls working progress and ensures its performance in compliance with initial features. That is why it controls all pedagogical activities by managing the educational activities of the institutes and supervises the allocation of the financial and human resources necessary to carry out these activities.

For instance, in 1998-1999 general number of registered participants of CNED was 401343 , including 58668 people within the framework of regulated training from the initial level to the bachelor's degree, 2167 - in the courses of support and support of schools, 21140 - in supplements and 46466 in the summer. Enrolled students, from elementary education to undergraduate, can complete full education regardless of their age or position (completed classes), continuing education (resumed after a break or reorientation), additional education (students in schools that are unable to study certain subjects), support (students at school who wish to help in one or more subjects), summer courses (consolidation of the material learned and preparation for the next academic year). They can also be associated with adaptation and school integration, or even suffer from such shortcomings that education in the institution is impossible. Participants of the CNED's programs can also be abroad. The CNED's courses can be used both for initial education as well as for further social advancement. In summary, we can say that no educational institution has such a different audience by age and educational situation as CNED. Despite this huge number of users, the system works. CNED manages an almost industrial organization, with many professions and management imperatives that must constantly align with educational goals.

Working with CNED participants (subscribers) takes various forms: training by phone, audio recordings in languages, use of the Internet and of the electronic campus, an interactive television program etc. In general, as demonstrated by this long-term training practice, this educational service is highly appreciated by students, even if it varies widely depending on the level and discipline, and if the use of modern means of communication has not yet become widespread, which is especially important for developing Frenchspeaking countries. Nevertheless, it should be noted, that CNED subscriber works alone most of the time and that he or she needs more than any other student the interactivity provided by modern methods of communication: the Internet, electronic messages, video, chat [5].

CNED subscribers can not, by definition, achieve the results that would be comparable to the results achieved by the students of the internal mode of study, taking into account the difficulties connected to distance, isolation and disability. In terms of attendance, it should be noted that school dropout for students under the age of 16 overwhelmingly corresponds to enrollment after recovery, return to France or settled life. Of course, up to the age of 16, the attendance of CNED courses is controlled as in a school. According to CNED, for those who entered the general education lyceum, half are really diligent, $70 \%$ in the vocational lyceum, where homework is more numerous. These remarks, of course, have consequences for the final exam results.

As for the results, they are comparable with internal mode of education, the difference with the results obtained by students in internal mode of education is not so significant: at the session in June 1998, 40.4\% versus $79.1 \%$ for bachelors of general education, $49.7 \%$ against $79.6 \%$ for the technological one. First of all, it should be noted that without CNED most of these people would not get bachelor's degree. Thus, it seems that this institution in 1998 allowed to $41 \%$ of registered people who have health issues, $49 \%$ of professional athletes, $47 \%$ of registered people with "traveling" parents, $42 \%$ of young people to refuse from traditional school system, to $50 \%$ of young people to find "freedom and flexibility" (internal survey of CNED).

Teachers, cooperating with CNED, are numerous (4499 in January 2000, but really it is from 5 to 6 thousand people including all temporary personnel) and have very different 
statutes. Many of them have issues of continuous training and oversight by inspection bodies. All of them are distributed as follows: 76 seconded, 23 part-time, 503 re-employed, 657 reorganized, 89 provided by academies and 3151 temporary workers. This list is sufficient to take into account the difficulties in personnel management. There are even more of them as a result of geographical spread and health status of teachers engaged in reemployment or rehabilitation, as a result of the constant renewal of temporary workers and the fact that CNED is not recognized as an academic education per se, although its CEO holds the title of Rector of the Academy. Currently, there are consultations between CNED, academies and the ministry, and they should lead to a memo that will better take into account the specifics of the institution. If CNED is an indispensable institution that allows teachers who are ill or have difficulties to continue their studies, its activities, especially during the period when the competition opens, should be based on specialists in distance learning methods. Personnel training is crucial. A teacher involved in the work of CNED should master not only his or her discipline or specialisation but also methods specific to distance learning.

With regard to the development of technologies and methods of distance learning, significant steps have been taken here. CNED created a model school on these issues at Futuroscope (distance learning training school), which is a unique teaching and research center in the world. It is visited by delegations from all over the world, the skills that are developed there bear certain fruits. Success is largely determined by the training of CNED teachers, on whom the future of the institution depends. The need for teachers who are familiar with remote work in networks is becoming more and more obvious. This already means that the central issue for the future of CNED is the question of its modernization or, more precisely, its ability to instill in all its staff, without exception, the will and the ability to use modern communication methods in the very process of training, in order to really take into account the specifics of working at a distance.

For CNED, the current development of information and communication technologies, digital revolution, multimedia represent a breakthrough in methods and technologies for providing educational material. But even more than schools, CNED, whose activities by definition involve remote interaction, must adapt to constantly changing realities. Today there is a new educational agreement on distance learning and CNED made certain efforts on modernisations, scale and success of which deserve a high mark. This movement takes various forms, which will be detailed: electronic campus, CD-ROM production, interactive television programs, virtual classrooms, etc., and which correspond to the concept of distance courses or training. However, practice shows that the use of digital methods has not yet been generalized and systematized, so today CNED is working in this direction. In its work, CNED uses various organizational structures when conducting classes, which include: an electronic campus, interactive TV shows and virtual classrooms.

\section{Electronic campus}

Campus enjoys significant and growing success. Users come there to get information before registering (catalogs, skill assessments, online tests, etc.), but above all the services provided to registered users (various forums, resources, links, training courses, electronic homework banks, etc.). The ergonomics of the site, the ease of navigation, and the educational sequence do not cause any complaints. For some courses, there is a great integration of interactive and animated products, sound and image. A CD initiated on the Internet is also available online. Thus, the electronic campus is a perfect shop-window for CNED and represents a whole range of educational services for registered users. The demand for expanding the site's services is very high. So, online college-level trainings, as well as grammar studies in German, Italian and Spanish for high school students, are freely available today. 
With limited access, for registered users only, a distinction is made between elementary, middle and high school. Training materials are available for the CM1, CM2, and CF2 levels for primary education. In college, in the sixth grade, a student can download courses of English, Music education, French, Mathematics, History-Geography, Life Sciences and Earth Sciences and course annotations in fine arts and technology, as well as the above courses plus Physics-Chemistry and annotations of all courses. In the fourth grade, it is possible to download courses in French, mathematics, history-geography, life and Earth sciences, physics-chemistry, as well as annotations of all courses. In the second grade, students have access to educational materials for the initial introduction to the course of mathematics and geography. In graduation grades (first and terminal (last)), a registered participant can download some of the courses in history, geography, mathematics, economic and social sciences, life and Earth sciences, physics.

\section{Interactive $T V$-shows}

CNED provides its subscribers with 120 hours of live satellite TV broadcast per year, received at 700 sites across the country, including high schools and colleges, as well as a catalog of videograms with a duration of more than 700 hours. In cooperation with the Center of vocational training for adults, AFPA (Centre de formations professionnelles qualifiantes pour adultes) and the Institute of Social Management, a satellite TV training program was created for continuous broadcasting of training courses.

This technology generates interest in students. For example, classes of middle school or college can prepare a program with their teacher and take part in it in life in order to conduct a dialogue with a teacher or a scientist invited by CNED. In practice, however, many high schools and colleges find it difficult to adjust their schedules when they broadcast and are content to record those broadcasts. However, at the same time, they lose interactivity, which is a disadvantage of educational television. The flexibility of the Internet its direct interactivity, and the ability to watch TV shows with its help will undoubtedly make a difference. Interactive television broadcasts allow CNED to penetrate widely into educational institutions, as well as create study groups from registered users, which in France are called virtual classrooms.

\section{Virtual classrooms}

This educational approach of CNED, which is a consequence of the generalization of digital technologies, caused the need to introduce a new form of the learning group of students: virtual classrooms. Virtual classroom is a functional educational unit in which the student, in relation to other students, is at the center of the educational system, in which the teacher plays a multiple role in the transfer and construction of knowledge, in the management of the cognitive process of the students.

This project is aimed at solving certain difficulties of distance learning, exacerbated by existing communication methods: first, the subscriber attends a "school open to the world" thanks to networks, but he or she is always alone, without direct contact with the teachers or peers. Secondly, the use of networks reduces the study time: the student attends classes in real time, performing tasks with its subsequent online correction. Therefore, CNED implements this project for each of the three levels of compulsory education, primary, secondary and high school. According to CNED, this project should be implemented stageby-stage or level-by-level. Minimal level is an exchange of home works and their correction online. It is hoped that any student who wishes can easily access this service and also move on to the next stage - online tutoring, open on campus, but which is still exceptional throughout the school year, outside of summer courses. The next levels already constitute "virtual classrooms": permanent groups of learners with permanent teachers using the forum, "chat", video conferencing and groups of registered learners who are in constant contact and are combined with real classes. This last stage is very promising and 
illustrates well that, under the influence of digital communications, the separation between distance education and face-to-face learning is becoming less and less noticeable.

Thus, CNED opens possibilities for modernisation with the purpose of analysis of consequences for education and the role of the teacher. Despite some difficulties, CNED offers fully integrated services, complete educational space with courses, resources, means of distant communication in real time or with a small lag. According to the French pedagogical community, it is necessary to extend this modernization to all types of education, including compulsory education. Even if CNED is in a competitive market today, the use of networks should be offered to all registrants who want to do so. The CNED public service requires this. Mainly due to the importance, quality and innovation of its achievements for the public service, the Center strengthens its reputation and finds its best assets in a competitive environment. This means that the training of teachers in new distance learning skills must be ongoing in order to turn them into real experts in the field of using telecommunications networks in education.

CNED performs two main functions. First, in relation to its members, CNED often offers a single chance to learn or a unique opportunity to return to continuing education or, finally, to improve on traditional learning. Secondly, and it is newer, CNED, through its practice and innovation, is also involved in improving the functioning of the entire education system, internal mode of studies. Since distance learning is directly transformed by digital communication technologies, the educational changes implemented by the institution are the subject of reflection, which also concerns internal mode of studies. It can be said that thanks to these techniques, or rather, thanks to the teaching methods, they are getting closer: online lessons and exercises, tasks of new teachers, etc. This is how learning is presented in the classroom today, which introduces a certain form of distance into the learning process and the teacher-student relationship. This is what is called a "hybrid education". Therefore, it should be noted that CNED will be even more integrated into the French education system and that it will no longer be just "default learning". [5]

\section{Results and discussion}

At the present stage of the development of distance learning, the French Ministry of Education relies on the concept of deploying the so-called digital workspace in the education system. Digital working space (Espace numerique de travail - ENT) - is an integrated set of digital services selected, organized, and delivered to the educational community of one or more schools in a trusted environment. In [7] there is a definition of this term "Digital working space (ENT) refers to digital service selected, organized, and delivered to all interested parties in educational society of one or several school schools within the trust defined by the ENT Master Plan and its annexes."

The concept of a digital workplace is directly related to the concept of a digital workplace. It is a single entry point that allows the user, according to their profile and authorization level, to access their services and digital content. It offers a place for sharing and collaboration between its users and other communities related to the school or institution. From kindergarten to high school, ENT is used daily in computer labs to help create learning situations that promote student autonomy and collaboration. ENT also contributes to continuity of education at school and at home, its members work on interdisciplinary projects and enrich their connections with each other [7].

ENT is presented as a modular and extensible set of integrated or related services that can interact with each other. ENT meets the definition, reference architecture, and requirements and recommendations of the digital workspace master plan (SDET). This tool is involved in the structuring of the digital educational space. Its generalization is a strong axis of the Ministry of Education's digital education policy. 
The basic services (core) are those that all user services are based on. User services are divided and organized into service typologies that take into account the pedagogical and educational spaces. It should be noted that the client part of ENT is currently designed for multi-channel, multitasking support and that it goes beyond the framework of an ordinary web-browser client representing mobile clients, while the other part of ENT provides materialization of the needs of increased exchange and collaboration between users.

ENT offers services:

- $\quad$ educational: digital resources, shared workplaces and cloud storage of information for students and teachers, collaboration tools, blogs, forum, virtual classrooms, etc.;

- $\quad$ support of school documentation: grades, roll books, schedule, diaries etc.;

- communication: exchange of messages, personal and family information, "chats", video conferences etc.

- Main services of ENT:

- integration services (data import/export; provision of external/internal services; provision of data to services);

- $\quad$ security services (identification and authentication; authorization; dissemination of identification information; application of security policies; detection and prevention of security breaches);

- $\quad$ portal services (presentation; portal setup; multi-channel management; search engines);

- $\quad$ support service (administration and back office; user assistance; information about the location and rental of equipment).

User services of ENT:

- communication and collaboration services (email; cloud storage for sharing and collaboration; instant messaging ("chats"); information display; web publishing; audio and video conferences);

- information and documentary services (address book; calendar of events; research service; bookmark management; access to editorial educational resources; document management);

- student support services (textbook/diary; individual monitoring of students; class schedule; communication/correspondence);

- educational and training and production services (audio and video tools; multimedia content creation tools; office tools; educational trajectory management);

- $\quad$ support services (managing user groups; storage and file sharing space; setting up a user environment; notification service; booking accommodation and equipment; assistance).

Students, parents, teachers and administrative staff can access these digital jobs and services from any device connected to the Internet. This is a digital extension of an educational institution or its digital information and educational environment.

In the context of successive project applications since 2015, the volume of equipment, especially individual mobile, for students and teachers is constantly growing. At the beginning of the 2016 school year, 103 out of 108 local governments were digitally involved in equipping 1,668 secondary schools. 239 institutions have already received equipment during the 2015-2016 academic year, the rest received it during the 2016-2017 academic year. In November 2017, a new project competition was announced to achieve the goal of reaching $50 \%$ of the colleges involved in the plan of digital education. Schools affiliated with colleges participating in the digital plan can also, under certain conditions, use this equipment. Today, there are already 1817 schools $[5 ; 8]$.

The Ministry has a policy of supporting the development and dissemination of digital educational resources. The various tools for implementing this support policy are presented in the following forms: 
Edutheque (Edutheque, ressources pedagogiques, culturelles et scientifiques pour les enseignants - Library, educational, cultural and scientific resources for teachers) [4]. The Edutheque program provides teachers and students with free and secure access to digital educational resources from the offerings of major public cultural and scientific institutions with which the Ministry has partnered, as well as scenarios for the use of educational programs offered by academies. It is intended for all primary and secondary school teachers who can register on a dedicated portal using their professional address or receive it directly through their ENT digital workspace.

BRNE (Banque de ressources numeriques pour l'Ecole - Bank of digital educational resources for secondary schools) [1]. The Bank of digital educational resources for secondary schools provides teachers and students with resources (content and tools) to enable them to learn by organizing events in a digital learning environment, classroom support, lessons, learning situations, testing, monitoring and evaluating skills that have been worked out. They consist of content and related services for writing documents, courses or assessments and are organized by training cycle.

Myriae (le portail de recherche et de presentation des ressources pour l'Ecole - Portal of research and resource presentations for schools) [9]. Myriae is the first portal for the research and presentation of digital resources for the school, this new service is offered by the Ministry and the Sapore Network to help teachers in their teaching practice. Myriae is also available for parents to support their child while learning.

Edu-Up (le dispositif Edu-up, un soutien a la production de ressources numeriques pour l'Ecole - Support system for the production of digital resources for schools) [6]. The work of this system is aimed at solving the following three tasks:

The implementation of this system is carried out by various institutions, which are subject to certain requirements. Eligible participants are legal entities, regardless of their legal form, which carry out economic activities. They can submit a project in partnership with research laboratories.

The system is aimed at supporting the content industry and, in particular, startups in this sector, it is open to any legal entity (associations, foundations, public institutions, etc.). This allows us to support industry-specific innovative projects with high added value for the education sector.

Support for the production of digital educational resources is aimed at projects based on innovations in the educational, technological, economic and organizational spheres. The Edu-Up system is designed for projects that create innovative related content and services, from kindergarten to level III (BTS, CPE), regardless of the disciplines or areas of study and that meet the standards of national education. In particular, projects are planned for 2021-2023 aimed at promoting content and related services:

- $\quad$ with the use of artificial intelligence;

- modeling, immersion and virtualization of educational objects;

- collaboration of students and/or teachers;

- $\quad$ aimed at supporting the priorities of the Ministries, in particular, the promotion of inclusive schools.

Edu-Up aims to develop and provide teachers with educational services/tools/support resources to differentiate and personalize their students' learning through innovative solutions based on artificial intelligence (AI).

\section{Conclusions}

The above analysis of the history and current state of distance learning and the use of digital technologies in the French national education system shows that this educational practice is at a 
fairly high level and can serve as an example for the implementation of this concept in other countries of the world. This has become especially relevant at the present stage in connection with the susceptibility of mankind to various external threats of a technogenic or biological nature.

It should also be noted that The French Ministry of National Education is currently pursuing a policy of widespread introduction of both purely distance and hybrid education, taking into account the spread of the pandemic. Here is what the minister, Frederic Vidal, says about this at the beginning of the 2020-2021 academic year: "Last academic year, it was very difficult for students, because they did not have internal mode of study for a whole semester. I hope that we will be able to restore internal mode of study for everyone as much as possible," and added that she would like to see as many students as possible in the classrooms of universities. However, Frédéric Vidal still recommended maintaining a "hybrid" learning system that combines the physical presence of students in the classroom and distance learning. She suggests spending money allocated by the government to finance "digital development projects", such as, for example, "training teachers to use computers, hiring new technicians, buying the necessary equipment" [1].

\section{References}

1. V. Frederik, French universities will open 30 thousand new places, https://regnum.ru

2. Banque de ressources numeriques pour l'Ecole, https://eduscol.education.fr

3. CNED: National center of distance learning, https://www.orientation.com

4. Ediscol, https://eduscol.education.fr

5. Education.gouv.fr, https://www.education.gouv.fr

6. Edu-Up, https://eduscol. education.fr

7. Espaces numeriques de travail, https://eduscol.education.fr

8. M@gistere, https://magistere.education.fr

9. Myriae, https://myriae.education.fr 